\title{
Scientific Substantiation and Methodical Basis for Creating Cards of Determining Potential Hazards of Sloping Land of Azerbaijan (on the Example of Akhsuinsky and Ismayilli Districts)
}

\author{
RAE ZH Aliyev* \\ Erosion and irrigation Institute of the Azerbaijan, Azerbaijan \\ *Corresponding author: RAE ZH Aliyev, National Academy of Sciences, Azerbaijan \\ Submission: 悳 March 28, 2018; Published: 眥 April 06, 2018
}

\begin{abstract}
The article examines the issues soil erosion a risk traditionally rapidly growing with agriculture in tropical and semi-arid regions, which is particularly important for its long-term effects on soil productivity, removing topsoil, than soil formation processes can replace it due to natural, animal and human activities, in the example, excessive grazing, cultivation, deforestation and more mechanical farming and sustainable agriculture. Studied the spatial characteristics of grass and arable land formations, their positive impact on anti-erosion installations research. Developed methodological framework mapping of soils from the threat of erosion.
\end{abstract}

Keywords: Soil fund stability; The threat potential; Formation; Arable; Sediment yield

\section{Introduction}

In recent years, the development of agriculture comes increasing, due to the increasing population in various countries. Average annual growth for the last irrigated land of the TWENTIETH centuries was over 3 million hectares [1]. Irrigated area on the globe exceeded 220 million hectares. The total area of the Republic is 8641.5 thousand ha. Of these, 3610 thousand hectares, or $43.23 \%$ of the soil of the Republic Fund places in one or another degree were subjected to erosion $[2,3]$.

Here historically formed complexes with environmental problems. In the most precarious status of land resources, which almost everywhere in varying degrees subjected to degradation, the intensity of which depending on terrain parameters morphometric climatic and soil-plant conditions, as well as economic activity degree often reach catastrophic proportions.

This contributes to the destabilization of the ecological situation in the Republic [3,4].

In Azerbaijan, in addition there is the problem of salinization of soil degradation. The Republic is described as a land-hungry country, where per capita accounted for 0.2 hectares of arable land. It should also be noted that in Azerbaijan there are also lowland conditions slope crossed conditions, which requires a special approach to technologies and technical means of irrigation.
Being a mountainous country, Azerbaijan is characterized by complicated natural conditions cool physiographic areas-greater and Lesser Caucasus, Kura-Arax River lowland and the Talyish mountains, strongly distinguished from each other on geological structure, climate, soil and vegetative cover, , terrain slope, which range from 1 to 40 and more [3].

Highly developed in the Republic, existing in the nature of almost all types of erosion.

Soil erosion is a serious problem throughout the world. Soil erosion is a serious environmental, economic and social challenges; it's not only lead to land degradation and loss of productivity of soils, but also threatens the stability and health of the Society of universal and sustainable rural development in particular in mountain regions of the Republic (as Shamakhi, Axsu, Ismailia, Gabala, etc.) soil erosion is the removal of topsoil than soil formation processes can replace it due to natural, animal and human activities such as overgrazing, cultivation, deforestation and more mechanical farming $[3,4,5]$.

Spatial characteristics of herbaceous formations and cropland in the objects of study

A review of the literature devoted to soil erosion and its prevention in Azerbaijan, confirms the positive impact of antierosion herbaceous formations. 
A study conducted by us, under the leadership of Aliyev [2] in Terter PARADISE (2008-2010) and Shamakha OEB Institute erosion and irrigation NANA (2011-2013) on the effect of vegetation on pastures in the runoff and sediment yield showed significant influence of runoff and sediment yield. Establishment of control factors of vegetation and water on the slopes of the motor way, Shamakhi OEB was the reduction of vegetation water cause erosion to intercept rainfall, increase water infiltration to soil fertility, interception of runoff on the soil level surface and stabilizing soils under coarse ground $[1,3]$.

Analysis of properties of arable land in Axsu district height and slope of the terrain showed that up to $60.0 \%$ of their area is located at an altitude of more than $500 \mathrm{~m}$ from the sea level. On the basis of land-use maps, it was found that the main plant, grown on arable land in the region, vineyards, orchards, wheat, legumes and forage crops. It belongs to the Group of plants that have good ohranami properties in relation to soil and besides, rather it tolerates water shortages during the growing season.

Cultivation of wheat imports, together with appropriate machinery, should to a large extent, protect arable land in the region from water erosion. The selected for the analysis region of Azerbaijan, located on the Southwestern slopes of the great caucasus are three types of herbaceous formations: pastures, Green land -steppe.

Their location depends on various factors surrounding the region Wednesday. Placing herbaceous formations, in terms of height and slope, was analysed within the boundaries of Axsu district. In this area they occupy $24 \%$ of the total area, including: grassland-52\%, green lands, almost $28 \%$ and $20 \%$ of the steppe.

The most extensive high-altitude pastures have intervals, placed at an altitude of $1400 \mathrm{~m}$ above sea level.

In high-altitude $600-70 \mathrm{~m}$ intervals and $700-800 \mathrm{~m}$ number of largest pastures, respectively 19 and $20 \%$ of the total area of the territory. Almost $50 \%$ of pastures is located on slopes with a gradient $10-18 \%(6-100)$, and in the lower grades of slopes- $0-6 \%$ (up to 30 ) and 6-10\% (3-60)-20\%. Pretty much of $7.5 \%$ is on the slopes with inclines of up to $27 \%$ (150). Green lands are located at an altitude of $1000 \mathrm{~m}$ above sea level.

Largest area-60\%, are at a height from 200 to $50 \mathrm{~m}$ above sea level (by 20\% in areas of 200-300, 30-400 and 400 and $500 \mathrm{~m}$ ). More than half of these grassy \% 54-formations is located on slopes with a gradient $10-18 \%(6-100)$ and $22 \%$ with a slope of less than 6-10\% (3-60).

Steppe vegetation, often used as winter pastures, is observed in the lower altitudinal zones. In Axsu district, they are below 300 $\mathrm{m}$ above sea level. Almost $70 \%$ of the footprint is located below 100 meters above sea level and $98 \%$ on the gentle territories or lands with a slight slope from 0 to $6 \%(0-30)$. Areas covered with herbaceous vegetation formations are also dry river valleys. They occupy less than one per cent of the total area to be analyzed.
There are up to a height of $400 \mathrm{~m}$ above sea level and $95 \%$ on flat or gently sloping areas $[1,3,6]$.

The actual problem is erosion caused by caused:

a) mismatch plant species in a mixture of perennial herbal and leguminous plants,

b) too many cattle per hectare of pasture,

c) grazing animals on too steep slopes, especially with southern exposure

d) too early onset of grazing.

Reduction of the intensity of agricultural production and, especially, the intensity of grazing animals, as well as adaptation to the conditions of grazing techniques habitats above the grassy formations will strengthen their anti-erosion value.

\section{Methodological framework mapping of soils from the threat of erosion}

Map of the threat from surface water erosion was established on the basis of: slope, soil maps and maps of land use map slopes received as a derivative of the layer digital elevation model (SRTM 90 WGS 1984), and then the retrofit to the erosion model in their class bias. Soil map was victimization and editorial processing.

The primary material was scanned map with an average magnitude of rectified lined topographic maps (1:100 000), and classified in 5 groups of sustainability the soil leachate may run off. Land use map was also based on scanned maps victimization land cover classificationtion system-FAO [1:50 000 scale 3.5].

Based on the results of the research, the following erosion and patent risk maps of the axsu and eastern parts of the Ismayilla region created based on GIS technology, respectively, were compiled.

Maps a threat from erosion (potential and actual) was established on the basis of Polish methodology, given the natural conditions Azerbaijan and list of legends to soil the soil map of Azerbaijan. Map of the actual threat from erosion was established way of reduction of degrees of potential danger from erosion, with accounts of the main land use categories (forests, permanent grassland, degree and arable land).

For forest land and permanent grassland, which possess a very considerable degree of functions ant erosion erosion threat reduction was at 3 units.

For the steppes on the reduction unit 2 was adopted, while agricultural areas only 1 unit (Table 1) [2,3]. The large change in average annual rainfall amounts axsu area was a partition into two geographical parts: dolinnuju (South), where the average annual rainfall is within $300-800 \mathrm{~mm}$, as well as mountain-precipitation is higher $800 \mathrm{~mm}$.

In the example of Ismailia district, because of its typical hilly topography, to map the potential erosion were accepted criteria 
relating to mountain territories. Data on mean annual precipitation $\quad[1,3,6]$. Analysis of the threat from erosion for agsu district showed were obtained from Atlas of Azerbaijan Republic for the year 2007

Table 1: Criteria for identifying threats from potential and actual surface water erosion.

\begin{tabular}{|c|c|c|c|c|c|}
\hline \multirow{2}{*}{$\begin{array}{c}\text { Soil Leachate } \\
\text { May Run Off The } \\
\text { Sustainability Group } \\
\text { Unstable: }\end{array}$} & \multirow{2}{*}{$\begin{array}{c}\text { Gradient } \\
\text { \% } \\
0-6\end{array}$} & \multirow{2}{*}{$\begin{array}{c}\begin{array}{c}\text { The Degree of Threat } \\
\text { From Potential } \\
\text { Erosion }\end{array} \\
1 \\
\end{array}$} & \multicolumn{3}{|c|}{ The Degree of Threat From Real Threats } \\
\hline & & & 0 & 0 & 0 \\
\hline \multirow{4}{*}{$\begin{array}{l}\text { mining-Brown, grey- } \\
\text { brown, heavy clay } \\
\text { : carbonate, } \\
\text {-tight, } \\
\text {-runaway under forest } \\
\text { or forest }\end{array}$} & $6-10$ & 2 & 0 & 0 & 1 \\
\hline & $10-18$ & 3 & 0 & 1 & 2 \\
\hline & $18-27$ & 4 & 1 & 2 & 3 \\
\hline & $>27$ & 5 & 2 & 3 & - \\
\hline \multirow{5}{*}{$\begin{array}{l}\text { Little sustained: } \\
\text { mining-Brown, } \\
\text { light grey, meadow- } \\
\text { argillaceous or } \\
\text { medium-clay alluvial } \\
\text { meadow or slightly } \\
\text { saline grey-brown }\end{array}$} & $0-6$ & 1 & 0 & 0 & 0 \\
\hline & $6-10$ & 1 or 2 or & 0 & 0 & 0 or 1 \\
\hline & $10-18$ & 2 or 3 & 0 & 1 & 1 or 2 \\
\hline & $18-27$ & 3 or 4 & 0 or 1 & 1 or 2 & 23 \\
\hline & $>27$ & 5 & 2 & 2 or 3 & - \\
\hline \multirow{5}{*}{$\begin{array}{l}\text { Medium resistant: } \\
\text { Meadow-gray, Brown, } \\
\text { medium-clay, clay- } \\
\text { saline or grey-brown } \\
\text { slightly saline }\end{array}$} & $0-6$ & 1 or 2 or & 0 & 0 & 0 \\
\hline & $6-10$ & 2 or 3 & 0 & 0 & 0 or 1 \\
\hline & $10-18$ & 3 or 4 & 0 & $0: 1$ & 1 or 2 \\
\hline & $18-27$ & 4 or 5 & $0: 1$ & 1 or 2 & 2 or 3 \\
\hline & $>27$ & 4 or 5 & 1 or 2 or & 2 or 3 & - \\
\hline \multirow{5}{*}{$\begin{array}{c}\text { Sustainable: } \\
\text { mining-Brown, grey- } \\
\text { brown, heavy clay: } \\
\text {-loose, } \\
\text {-medium density } \\
\text { steppe, slightly saline } \\
\text { dense or dense clay } \\
\text { bright chestnut, or } \\
\text { alluvial meadow }\end{array}$} & $0-6$ & 0 & 0 & 0 & 0 \\
\hline & $6-10$ & 1 & 0 & 0 & 0 \\
\hline & $10-18$ & 2 & 0 & 0 & 1 \\
\hline & $18-27$ & 3 & 0 & 1 or 2 or & 2 \\
\hline & $>27$ & 4 or 5 & 1 or 2 or & 2 or 3 & - \\
\hline \multirow{5}{*}{$\begin{array}{l}\text { Very resistant: Sandy } \\
\text { blonde gray-meadow, } \\
\text { alluvial-meadow } \\
\text { or alluvial silt or } \\
\text { sand-friable Prairie } \\
\text { mountain-Brown }\end{array}$} & $0-6$ & 0 & 0 & 0 & 0 \\
\hline & $6-10$ & 1 & 0 & 0 & 0 \\
\hline & $10-18$ & 1 or 2 & 0 & 0 & 0 or 1 \\
\hline & $18-27$ & 2 or 3 & 0 & 0 or 1 & 1 or 2 \\
\hline & $>27$ & 4 or 5 & 0 OR1 & 1 or 2 or & - \\
\hline
\end{tabular}

Table 2: The extent of the threat from surface water erosion the mountain part of axsu district.

\begin{tabular}{|c|c|c|c|c|c|}
\hline Degree of Threat & $\begin{array}{c}\text { The Potential } \\
\text { Threat (Ha) }\end{array}$ & \% & $\begin{array}{c}\text { The Real Threat } \\
\text { (Ha) }\end{array}$ & Difference & 2-1 \\
\hline 0 & 1692 & 9.17 & 16026 & 91.95 & 14334 \\
\hline 1 & 4359 & 25.01 & 722 & 4.14 & -3637 \\
\hline 2 & 8690 & 49.86 & 456 & 2.62 & -8324 \\
\hline 3 & 2350 & 13.48 & 214 & 1.23 & -2136 \\
\hline
\end{tabular}




\begin{tabular}{|c|c|c|c|c|c|}
\hline 4 & 216 & 1.24 & 11 & 0.06 & -205 \\
\hline 5 & 122 & 0.70 & 0 & 0.00 & -122 \\
\hline The sum of the & 17429 & 100.00 & 17429 & 100.00 & 0 \\
\hline 5 & 122 & 0.70 & 0 & 0.00 & -122 \\
\hline The sum of the & 17429 & 100.00 & 17429 & 100.00 & 0 \\
\hline
\end{tabular}

This is the greatest mountain refers to the territories in which the significant reduction of all degrees of erosion threat, sparked the growth of the territory, not exposed erosion, more than $81 \%$ (Table 2). In the area of lowlands erosion reduction is primarily concerned with $2,3,4$, and 5 degrees.

Area, subject to erosion threat 2 degrees was reduced from 5516 ha to 412 hectares. Territory subject to erosion threat 3 and 4 degrees, only 96 ha, and 5 degrees was reduction to 0 .
A higher percentage of territories with 1 degree of threat from erosion in the mountainous part of the region is associated with the presence of a small amount of forests and large crops of wheat (Table 3) [1, 2,7].Residents of the area placed in regions with a significant incline of the ground, which increases the percentage of the highest degree of potential danger from erosion. Almost $48 \%$ of the analyzed of Ismailia district is threatened by erosion, 3.4 and 5 degrees (Table 2 \& 4).

Table 3:The extent of the threat from surface water erosion valley part of agsu district.

\begin{tabular}{|c|c|c|c|c|c|}
\hline Degree of Threat & $\begin{array}{c}\text { The Potential Threat } \\
\text { (Ha) 1 }\end{array}$ & $\%$ & The Real Threat (Ha) 2 & Difference & $2-1$ \\
\hline 0 & 35122 & 44.38 & 37377 & 47.23 & 22.55 \\
\hline 1 & 37002 & 46.76 & 41247 & 52.12 & 4245 \\
\hline 2 & 5516 & 6.97 & 412 & 0.52 & -5104 \\
\hline 3 & 1381 & 1.74 & 96 & -12 & -1285 \\
\hline 4 & 112 & 0.14 & 5 & 0.00 & -4 \\
\hline 5 & 4 & 0.00 & 0 & 100.00 & 0 \\
\hline
\end{tabular}

Table 4:The extent of the threat from surface water erosion the mountain part of ismailli district.

\begin{tabular}{|c|c|c|}
\hline Degree of Threat & The Potential Threat (Ha) & 1.05 \\
\hline 0 & 1556 & 33.97 \\
\hline 1 & 50367 & 17.11 \\
\hline 2 & 25375 & 11.62 \\
\hline 3 & 38095 & 10.55 \\
\hline 4 & 17232 & 100.00 \\
\hline 5 & 15648 & 148273 \\
\hline
\end{tabular}

\section{Conclusion}

A very big impact on the reduction of the intensity of surface water erosion raises some concerns about the sustainability of the advanced technologies used in the work methodology for the study area. In this regard, it would seem appropriate for field verification data, taking into account the impact of land use on washing away topsoil [8].

Another issue not related to the influence of surface water erosion, is the development of the territory of landslides. They create a large loss for Azerbaijan's infrastructure and may be subject to further study, including the modelling.

\section{References}

1. Aliyev HA (1978) Soils of the big caucasus within the Azerbaijan SSR, Baku, Azerbaijan, p. 157.

2. Aliev BH, Aliev ZH (2005) Irrigated agriculture in the mountain and foothill regions of Azerbaijan. Baku, Azerbaijan, p. 333.

3. Aliyev BH, Aliyev ZH (2000) Aliyev and erosion problems in Azerbaijan and ways of its solution. IZD-vo Zia-CPI Nurlan P. 128.

4. Aliev BH, Aliyev ZH (2007) Background on the crucial issue of agriculture in ensuring water resources management mountain and Foothill areas of Azerbaijan. J AAE 1(3): 179-182.

5. Aliev ZH (2007) Methods of optimum moisture supply of agricultural crops. NAS, Sat of the scientific research institute Soil Science and Agro chemistry, publishing house Elm, Baku, Azerbaijan, pp. 655-658. 
6. Babayev MP, Jafarov AM (2017) Modern soil cover of the greater caucasus. Baku, Azerbaijan, p. 344.

7. Aliyev ZH (2007) Task optimization of conditions of moisture of crops. J Rational And Complex Use Of Water Resources And Its Current Problems 1: $43-45$.
8. Genkel P (1982) Physiology of heat and drought protection of plants. Nauka, Moscow, Russia, p. 280. (c) (i) Creative Commons Attribution 4.0

For possible submissions Click Here

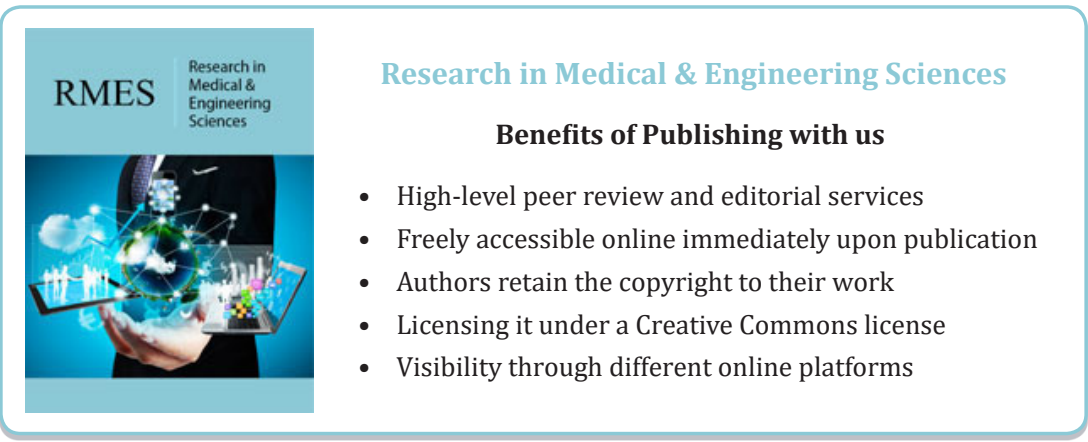

